\title{
Religión, Ritual y Vida Cotidiana en los Andes: Los Diez Géneros de Amarete; Segundo Ciclo ANKARI: Rituales Colectivos en la Región Kallawaya, Bolivia;
}

Mundo ANKARI, Vol. 6. Ina Rösing, Iberoamericana - Vervuert, Madrid, 2003

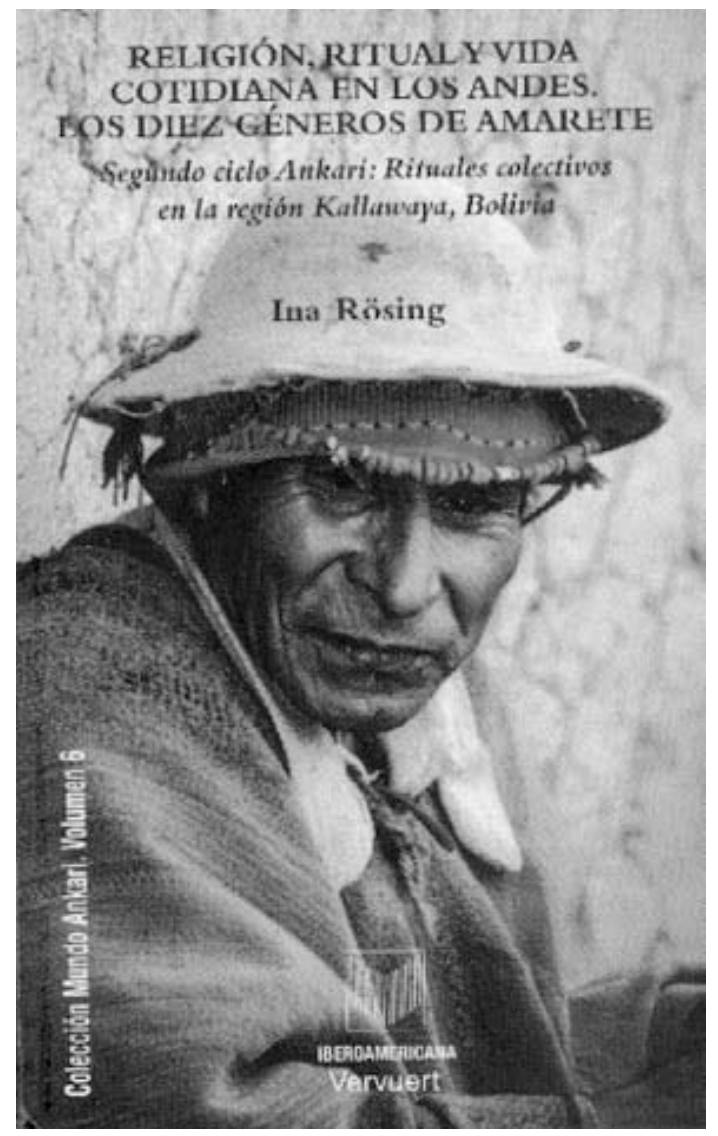

Comentado por Juan van Kessel*

Se trata de la edición en castellano del sexto volumen de la obra MUNDO ANKARI, sobre rituales de los Kallawayas de Bolivia. Recordemos: los 4 volúmenes del primer ciclo de la serie aparecidos entre 1987 y 1991 tratan de manera clásica y absolutamente definitiva sobre los rituales curativos de los Kallawayas en el círculo de la familia (1). El segundo ciclo investiga sus rituales colectivos y pretende "superar los déficit en el tratamiento de estos rituales". El volumen 5 trata de los rituales para llamar la lluvia, y el actual volumen, con el extraño título "Los diez géneros de Amarete", trata de los rituales colectivos en Amarete, una comunidad particular de la región Kallawaya, que merece atención especial por la curiosa organización social en que se basan sus ceremonias: "los diez géneros". Son géneros simbólicos de las personas con amplias repercusiones prácticas en la vida cotidiana, la religión y el ritual. Su fundamento es el género de la chacra que cada comunero, tanto hombre como mujer, posee y transmite a sus hijos (pp. 106-107). Así se encuentran: hombres masculinos, hombres masculinos-masculinos, hombres masculinos-femeninos, hombres femeninos-masculinos, hombres femeninosfemeninos, mujeres masculinas-masculinas, etc. Curioso es también que los amareteños pueden cambiar su género simbólico, de manera que entonces deben sentarse, caminar, bailar, actuar y ofrecer sacrificios de una manera diferente a la de antes. Es el caso de algunos cargos de representación comunal con género propio. $\mathrm{Al}$ asumir un cargo con género, se deja a un lado el propio género de chacra por el tiempo que dura el cargo. En última instancia, el género simbólico es determinado por el sol (salida/ocaso) y el cuerpo humano (derecha/izquierda) y sus dos indicadores resultan ser hanan/hurin (arriba/abajo) y kuraq/sullk'a (mayor/menor).

La pregunta impaciente del lector es: El sistema de los múltiples géneros simbólicos, ¿es algo más que una simple curiosidad? ¿Tiene un real sentido transcendental para el mundo amareteño? Sin duda es este el caso. El género (biológico y simbólico) es el principio de la organización social y del orden cosmológico (cf. p. 636). La máxima es que "todo debe estar pareado, casado" - cada cosa con su contraparte: ofrendas, chacras, aguas, rituales, dirigentes, etc.- para que sea completa, estable y equilibrada, operativa, eficiente y fértil. Sin su contraparte, las cosas no tienen sentido y no SON realmente. Me atrevo a interpretar el argumento así: en la cosmovisión del amareteño, y del andino en general (y prefiero decir: "en su pacha-vivencia") todo tiene vida, es ser viviente y debe ser alimentado, criado, regenerado a la manera de los seres vivientes. Todos los seres vivientes participan de la vida universal del pacha, el megaorganismo. En los grandes rituales colectivos -como verdadera tecnología simbólica- se regenera, alimenta, cría y fortalece la vida del pacha, del triple mundo de los humanos, la naturaleza y las divinidades. En síntesis, el ritual colectivo de Amarete basado en sus 10 géneros pretende juntar las cosas con su contraparte y casarlas para su regeneración, fuerza y duración. Así se asegura la vida del pacha: divinidades, naturaleza y runa (la

* Instituto para el Estudio de la Cultura y Tecnología Andina (IECTA), Av. Diego Portales 2046, Iquique. iecta@ chilesat.net. 
comunidad humana). El ritual colectivo de Amarete basado en los 10 géneros simbólicos es para reafirmar el orden existencial. El género que se recibe de la chacra expresa, a la vez, una sorprendente relación coexistencial hombre-tierra, concretamente del comunero con su chacra.

La autora confiesa (p. 640) que el descubrimiento y la explicación de los diez géneros simbólicos y de los principios en adjudicar el género simbólico le tomó seis años con largas estadías en terreno. El principio de los géneros simbólicos echa una luz particular sobre el ritual colectivo de Amarete, una luz indispensable para ver y entender el sentido émico? de los rituales. La autora los describe e interpreta bajo esta luz. Ina Rösing (en adelante: IR) cumple con este propósito y logra una verdadera obra maestra: inédita y de mayor relevancia en la producción antropológica contemporánea. Veamos la estructura de la obra.

El libro con sus 878 páginas está articulado en tres secciones. Encontramos dos capítulos introductorios, que describen la geografía y el contexto social de la región, definen el objeto de la investigación y señalan sus premisas metodológicas, las que por su carácter innovador en la investigación sociocultural merecen que las destaquemos más abajo. Se señala también la impresionante base de datos de este volumen registrada en decenas de libros con apuntes de campo, en centenas de cintas grabadas y transcritos en varios miles de páginas, y en muchas centenas de excelentes fotografías. Luego la autora presenta sin más preámbulos el tema mismo de los diez géneros y su notable importancia en la vida de la comunidad. IR agrega amplia información sobre la historia de su investigación y su insólita odisea como investigadora. Con esta información previa, la autora describe (cap. 3) la vida en Amarete, a partir de su geografía sagrada, articulada, y de su concepto del tiempo con un calendario festivo extraordinariamente rico en que a cada paso se encuentran las reglas relativas a los géneros. Con un ejemplo-la labor familiar cotidiana del cultivo de la papa- IR muestra que es imposible cotidianizar el trabajo aparentemente profano y que el tiempo y el espacio siempre son especiales y de carácter sagrado. ¡Elocuente ejemplo! que le vale como un previo teórico muy significativo, porque enseña que las ocupaciones de cada día, el carácter sagrado del espacio y la articulación festiva del tiempo "sólo son tres polos de un mismo centro: la religión andina".

En la segunda sección (cap. 4-8), la parte principal del libro, la autora trata del ritualismo colectivo en que el tema de los diez géneros es el hilo conductor que atraviesa los cuatro rituales agrícolas cíclicos que ella describe: La papa en el ritual Irwi (cap. 4), el ritual Q'owa con el baile y la labranza de los varones másculinos y femeninos (cap. 5), la labranza ritual en el Jach'ana (cap. 6) y la huilancha en la cumbre de una montaña sagrada (cap. 7). Como complemento, describe un ritual amareteño de emergencia para llamar la lluvia (cap. 8).
En la tercera sección (cap. 9-10) la autora intenta descifrar la lógica de las temáticas de género y espacio, una lógica flexible, variable y llena de improvisación, que permite la innovación y la evolución del ritual conforme las circunstancias y contextos cambiantes (cap. 9). En el último capítulo ella compara el ritual amareteño basado en los diez géneros, con el de las otras comunidades kallawayas, demostrando así su absoluta peculiaridad. Luego revisa toda la literatura andina para reforzar esta conclusión y termina con un listado de las cuestiones que siguen abiertas y que muestran la urgencia de una investigación etnohistórica para entender el proceso enigmático de la formación y transformación del ritual kallawaya (cap. 10).

Ina Rösing (IR) tiene un estilo de escribir agradable y entretenido; sabe presentar la investigación como un desafío y la descripción de los hechos culturales como una aventura. Por otra parte, pareciera que la traducción desde el alemán ha sido tan cuidadosa y detallada, tan cercana al texto original, que a ratos afecta a la fluidez y la fácil comprensibilidad del texto español. La autora rechaza enérgicamente y con buenas razones la "antropología muda" de Wachtel, Rivière, Platt, y otros (p. 80). ("El yachac masculla una oración y procede a..." ¿Qué oración? No se sabe). Grato efecto de la "antropología hablada" de IR es la inclusión de gran número de oraciones andinas (transcritas en quechwa y castellano), extensas, hermosas, fuertes, que acompañan e interpretan los rituales irradiando andinidad y haciendo brillar la pacha-vivencia de los ritualistas andinos (ver: pp. 250257, 402-406, 442-449, 555-559, etc.). El libro contiene también 75 excelentes fotografías etnográficas que son más ilustrativas que largas descripciones verbales. Además de ello, IR logra facilitar considerablemente la comprensión del tema y el discurso, de por sí complejos, por el recurso de "cajas de sinopsis", 54 en total. Finalmente encontramos amplios y valiosos anexos de vocabulario, bibliografía e índice de autores citados, y un apéndice de 43 "reglas relativas a los 10 géneros de Amarete". Aparecen pocos errores de imprenta. El libro lleva también 15 croquis fotocopiados del cuaderno de apuntes de la investigadora, que le confieren la grata fragancia del campo y situaciones complejas y confusas, pero es lamentable que, en tan prestigiosa edición, estos croquis son difíciles de leer y, al menos en parte, casi imposibles de descifrar. Otra observación sería que en la base de datos, tan completa en su registro de los rituales, se echaría de menos -como rica vena no aprovechada- que no quedaron registrados y analizados la música y la textilería en el contexto del ritual colectivo. Para el antropólogo, éstas dos son también elocuentes portadoras de información cultural. Lo mismo vale decir también sobre la dieta y la gastronomía en el contexto ritual, que interpretaría el significado de la presencia y la actividad ritual de la mujer, y con mayor razón por cuanto IR lamenta el papel ritual demasiado pobre de la mujer amareteña. Se supone que la música de conjunto produ- 
cida en Amarete (mal llamada "folklórica") nunca es simple diversión, sino expresión ritual propia y orgánica; los tejidos, como las vestimentas llevadas en los rituales, las prendas y manteles usados para la mesa ritual, son también expresión de identidad y rol social, de cosmovisión y estructura religiosa.

Vale ir a una discusión crítica sobre la metodología investigativa que IR maneja en todas sus pesquisas kallawayas, pero que en este volumen ella aplica con mayor rigor y llegando hasta sus consecuencias. Como investigadora, IR se ubica entre los revolucionarios de la epistemología del saber científico que no aceptan el objetivismo clásico y con mayor razón rechazan el positivismo en ciencias socioculturales. En cambio, apuestan no al subjetivismo ni al personalismo, sino a la dialéctica y la intersubjetividad como base de la confiabilidad y la veracidad del conocimiento científico generado en la aventura de la investigación antropológica (2). De ahí también el interés de IR por una "antropología hablada", es decir, por los investigados tales como son: no objetos de estudio, sino seres humanos e interlocutores. La dialéctica y la intersubjetividad es la postura casi inevitable de todo investigador que adopta en forma consecuente las técnicas de la observación y la investigación 'participante'. La exigencia de neutralidad valórica y la pretensión de la objetividad más absoluta eran las características de la postura del positivismo clásico y la conditio sine qua non para 'generar conocimiento científico'. En cambio, en el ambiente de una epistemología de la dialéctica y en un proceso interactivo entre investigador e investigado que ha de generar el conocimiento científico, la postura intersubjetiva es la que garantiza la veracidad y la confiabilidad del saber científico en ciencias socioculturales. De ahí también que IR como investigadora participante incluye su presencia activa en el registro de los rituales colectivos. Ella nunca pretende un registro simplemente objetivo y anónimo; nunca disimula su presencia, tal como lo exigía en tiempos pasados el código de objetividad y cientificidad positiva. La vemos continuamente presente en el proscenio de la investigación. Ella participa en la acción registrada (p.ej. p. 336) y sus colaboradores participan en la investigación en calidad de verdaderos coinvestigadores de su propia realidad, y ya no como simples informantes locales (pp. 68 ss). Es la observación (e investigación) participativa llevada a sus consecuencias. Cuando IR presenta sus tres coinvestigadores indígenas como muy apreciados amigos de confianza y compadres ( $\mathrm{p}$. ej. las pp. 648 y ss.), es ésta la actitud consecuente de la observación (e investigación) participativa. IR, la investigadora académica, es al mismo tiempo la portavoz de confianza de los investigados, donde ellos como coinvestigadores no saben expresarse en el lenguaje académico: ella los interpreta. Atención: la posición de los "coinvestigadores" no es la misma que la del(a) investigador(a) académico(a). Además, aparece otra piedra en el camino: en el informe final, la investiga- dora asume el papel de traductora del lenguaje popular al académico. En la investigación participativa (la que en sus consecuencias llega a ser "investigación interactiva"; nada lo prohíbe), la perspectiva de la investigación depende, en parte, de la posición que ocupa la investigadora en el proscenio y de la postura valórica que ella lleva.

Vislumbramos en el libro de IR el supuesto que a los kallawayas -los coinvestigadores, sujetos de la investigación- corresponde también garantizar la confiabilidad y la veracidad del saber científico generado en la investigación intersubjetiva interactiva. De ser así, la autodefinición de los investigados, la autointerpretación de su propia realidad cultural, tiene cierta prioridad sobre la visión del académico que es una visión externa y desde fuera. La primera no reemplaza ni degrada la segunda, sino que ambas se complementan en el proceso de la investigación intersubjetiva, interactiva. Pero los mismos kallawayas pasan a ser la primera autoridad moral para sustentar la veracidad y por eso la cientificidad del saber generado en la odisea de la investigación. Al final, y como exigencia propia del método, encontramos que el ritualista de Amarete y los comuneros en general los sujetos de la investigación, y ya no simplemente su objetivo- han de reconocerse en la interpretación de su ritual y autorizarla de algún modo, como sello y garantía de veracidad. Es lógico que IR no se conforma con interpretaciones de tipo ético (pp. 759ss), que sólo representan la visión académica del investigador. Ella presenta una interpretación compartida. Efectivamente, la interpretación debe ser de alguna manera reconocida, adoptada y autorizada por los investigados.

Puntualizamos que -aparte de una epistemología dialéctica- este método participativo-interactivo llevado por IR está basado en dos componentes especiales: 1 . la presencia y actuación de la investigadora en el proscenio de la investigación, y 2. la participación de los kallawayas en calidad de coinvestigadores.

Sin embargo, esta metodología y la epistemología subyacente llegan necesariamente a su punto crítico. En la discusión al respecto, la consecuencia de su rigor es un punto criticable y criticado, pero también un punto justificable y sostenible.

1. La actitud y postura del investigador respecto a su objeto de estudio puede llegar a un punto crítico. IR no escapa a esta 'crisis'. Consecuente con su principio metodológico, ella se identifica 'émicamente', en visión y criterio, con sus coinvestigadores kallawayas. ¡CASI siempre! Ella asume desde la primera página una actitud de admiración por la organización social y ritual kallawaya, pero alguna vez abandona esta posición, p. ej. cuando se refiere a la interpretación de los ritualistas con respecto a catástrofes y desgracias naturales, explicándolas como castigo por errores en el ritual y por la deuda sacrificial. Entonces IR se expresa necesariamente en forma neutral, objetiva, distante, reservada; "En la opinión de los amareteños..."; "Según ellos...” (pp. 514-519). 
2. Otro efecto inevitable del método participativointersubjetivo (digamos ya: interactivo) es que la investigadora influye en el proceso formativo del ritual que ella investiga. IR lo reconoce (p. 678). Esta es una real consecuencia del método. El rechazo de la interpretación científica objetiva y valóricamente neutra en ciencias socioculturales, y la adopción del principio de la intersubjetividad como base del conocimiento generado, abren la posibilidad de la intervención del investigador en su objeto de estudio. Es más: la justifican dentro de exigencias estrictamente éticas. Esto es un elemento totalmente nuevo en el discurso sobre el conocimiento científico y en la metodología de la investigación sociocultural, postmoderna.

3. Otro efecto del método es que ya no se niega ni se disimula la relación emocional y afectiva entre el investigador y la comunidad investigada. IR lo reconoce y ella asume este compromiso. Tocando el tema del futuro incierto y la fe en la fuerza de la tradición amareteña, ella suspira: “...solo cabe compartir con los amareteños esta esperanza” (p. 681). Por lo mismo se explican y se justifican las expresiones dramáticas y nostálgicas de la autora (pp. 781ss.), haciéndose eco de la denuncia del "etnocidio del desarrollo (de la modernización, del inevitable cambio)", llamado también "holocausto al progreso". Impresiona también la frase final del libro donde IR pone de hecho su firma autográfica bajo la obra (3): "Irrefutablemente Amarete va a cambiar. Pero lo que Amarete hasta ahora ha realizado y creado, lo que ha configurado y desplegado constituye en todo caso una hazaña cultural fascinante a la que, con este mi libro, le quisiera levantar un monumento" (p. 785). Es la "antropología de compromiso'. Efectivamente, en la metodología de IR no hay rastro de la pretención de la 'neutralidad valórica de la investigación', pero ella demuestra que en ciencias socio-culturales se trata de una cientificidad diferente.

Lo anterior no significa de ninguna manera dar paso a cierta permisividad en los códigos de la metodología, ni una falta de rigor científico. La prueba está en el capítulo 10 del libro donde alguien podría reprocharle un excesivo rigor del método, un perfeccionismo irritante, una odisea casi absurda y masoquista. En los párrafos 3 y 4 (pp. 694-780) se trata de demostrar que la estructura social y ritual de Amarete basada en los 10 géneros es un caso único en la región de los kallawayas, en todo el mundo andino y en el mundo tout court. Sabemos que el desafío más difícil siempre es demostrar empíricamente que no existe un segundo caso; parece una misión imposible. Sin embargo, IR la asume, provocando en el lector más pragmático no solo admiración, sino también irritación, cuando se siente llevado por 85 largas páginas de sofisticados senderos para demostrar que "Amarete es único". El pragmático diría que este párrafo es sólo para el metodólogo y para el fiscalizador crítico. Para él, esta parte del libro vale como pieza digna del archivo. Nótese que, mientras el pragmático se irrita, el Prinzipienreiter entre los metodólogos quedaría insatisfecho, porque la prueba empírica de IR referente a la unicidad de Amarete no es (y nunca podrá serlo) totalmente impermeable y hermética.

Sin embargo, aun sin meterse en esta discusión queda la pregunta: ¿Se trata en estos párrafos "sofisticados" de un juego personal de IR, fascinada por el misterio de Amarete? ¡No! Los conceptos de los géneros simbólicos, sus principios y sus indicadores resultan ser definiciones y comparaciones salidas de la concepción de los amareteños, de su modo de concebir la realidad (ritual y social) local, no de la imaginación creadora de IR. Los conceptos relacionados de los 10 géneros de Amarete son, irrefutablemente, conceptos "émicos" (pp. 759ss.).

La conclusión de que "Amarete es único"-aunque parezca banal- levanta un problema mayor: ¿Cómo se explica que Amarete sea único? Los capítulos 9 y 10, que contienen las conclusiones del libro, son los de mayor interés para la formación de la teoría antropológica. Muestran una de las vías de un proceso de cambios rituales y de estructuras sociales. Las pp. 646-647 señalan ya el origen etno-histórico local de Amarete, y de su proceso de creciente complejidad del sistema de ordenación basado en el género. La comunidad de Amarete parece haberse aferrado tenazmente a este sistema de ordenación; lo elaboró y lo amplió constantemente conforme las nuevas situaciones. En cambio, las otras comunidades kallawayas parecen haber soltado poco a poco este principio de ordenación social y cúltico, al compás de los cambios socio-económicos y políticos. Resulta que la etno-historia puede ser muy local, conforme a: (a) los contextos locales cambiantes, y (b) las respuestas diferentes de los lugareños y sus dirigentes y ritualistas. IR habla de un proceso etno-histórico de traducción: se trata de la capacidad creativa local de traducir el ritual tradicional en un contexto nuevo, un proceso de traducción (p. 717). No parece aceptable que la aparición de un gran maestro ritualista carismático en la historia local, como Pasqual Tapia (compadre e informante principal de IR), sea un único y fantástico cometa en la historia kallawaya; debe haber una tradición ritual mayor. En una investigación etno-histórica podrían descubrirse los maestros de Don Pascual y la razón por la que precisamente en Amarete se haya desarrollado tan complicado y sofisticado, tan único e impresionante ritual colectivo basado en los 10 géneros simbólicos de los comuneros y la pacha, con sus cerros, chacras y agua.

Para explicar el extraño hecho que en todo el universo kallawaya sólo los amareteños se han organizado en base a los 10 géneros simbólicos y para conseguir más claridad en el bosque de las posibilidades e hipótesis, resulta definitivamente necesario desentrañar la dimensión etno-histórica de la investigación; una exhaustiva investigación etno-histórica para entender la formación y transformación del ritual local de Amarete. La autora es la primera en reconocerlo y sugerirlo (pp. 676, 680, 691). 
Sobre la investigadora: IR, la maestra investigadora, es admirable por su asombrosa capacidad de trabajo, su inagotable energía, su absoluto rigor científico. Admirable es también por su actitud de autocrítica y su exigencia hasta el extremo con respecto a su propia investigación. Como investigadora es perfeccionista, incansable. Ciertamente no peca de falsa modestia; muestra sin reservas su propia excelencia. En las partes de su investigación bibliográfica, critica implacablemente los vacíos y las deficiencias metodológicas de insignes colegas investigadores, pero siempre reconociendo cabalmente sus valores y valorando generosamente sus logros (p.ej. el cap. 10, en que valora y critica a P. Flores, N. Wachtel, T. Platt y G. Rivière). Como colega investi- gadora IR es tan respetable como temible. Como maestra investigadora ella sabrá, sin duda, potenciar el todo de sus discípulos.

Sobre la investigación: En mi opinión, la obra completa del MUNDO INKARI de IR es y será siempre un clásico en creatividad científica e información antropológica; y un abre-caminos para la metodología postmoderna en ciencias socio-culturales. La obra es una digna continuación de los tomos anteriores. Una investigación de largo alcance, de gran rigor, de mayor relevancia y que descubre una realidad cultural muy profunda, jamás sospechada e imposible de descubrir con una metodología positivista: demostrando que las grandes obras nacen no del robot académico, sino de un gran amor.
(1) El primer ciclo del Mundo Ankari (los Vols. 1-4) comprende:

IR: Die Verbannung der Trauer (Llaki Wij'chuna). Nächtliche Heilungsrituale in den Hochanden Boliviens; Mundo Ankari, Band 1; Nördlingen: Greno, 1987.

IR: Dreifaltigkeit und Orte der Kraft: die Weisze Heilung. Nächtliche Heilungsrituale in den Hochanden Boliviens; Mundo Ankari, Band 2; Nördlingen: Greno, 1988.

IR: Abwehr und Verderben: die Schwarze Heilung. Nächtliche Heilungsrituale in den Hochanden Boliviens; Mundo Ankari, Band 3; Frankfurt: Zweitausendeins, 1990.

IR: Die Schlieszung des Kreises: Von der Schwarzen Heilung über Grau zum Weisz. Nächtliche Heilungsrituale in den Hochanden Boliviens; Mundo Ankari, Band 4; Frankfurt: Zweitausendeins, 1991.
El segundo ciclo del Mundo Ankari comienza con el volumen 5 de la obra, titulado:

IR: Rituale zur Rufung des Regens. Zweiter ANKARIZyklus: Kollektivrituale der Kallawaya-Region in den Anden Boliviens; Mundo Ankari, Band 5; Frankfurt: Zweitausendeins, 1993.

(2) Con Peter Kloos podemos considerar el conocimiento intersubjetivo como el fundamento de la epistemología dialéctica y del saber científico en las ciencias socio-culturales de la época actual, postpositivista: P. Kloos, Filosofie van de antropologie, Ed. Martinus Nijhoff, Leiden, pp. 25 ss.

(3) Este modo personal de hacerse presente el antropólogo en su informe, es lo que Peter Kloos, o.c. (defensor de la postura intersubjetiva como fundamento epistemológico del nuevo método científico en ciencias socio-culturales, y como garantía de credibilidad y veracidad) señala como "la autografía del investigador" justificándola y exigiéndola por la misma razón que el artista tiene para firmar su obra, ya que se trata de su interpretación fidedigna de la realidad observada. 